\title{
FUNCTIONAL OUTCOME OF POSTERIOR STABLISING TOTAL KNEE ARTHOPLASTY
}

\author{
Ahmed Parvez, Tank Gyaneshwar, Singh Amit, Kumar Alok, Gupta Amit, Tomar Sagar
}

1. Associate Professor. Department of Orthopaedics, L.L. R.M Medical College, Meerut, Uttar Pradesh.

2. Assistant Professor \& HOD. Department of Orthopaedics, L.L. R.M Medical College, Meerut, Uttar Pradesh.

3. Junior Resident. Department of Orthopaedics, L.L. R.M Medical College, Meerut, Uttar Pradesh.

4. Junior Resident. Department of Orthopaedics, L.L. R.M Medical College, Meerut, Uttar Pradesh.

5. Junior Resident. Department of Orthopaedics, L.L. R.M Medical College, Meerut, Uttar Pradesh.

6. Junior Resident. Department of Orthopaedics, L.L. R.M Medical College, Meerut, Uttar Pradesh.

\section{CORRESPONDING AUTHOR:}

\section{Dr. Amit Singh}

Junior Resident,

Department of Orthopaedics,

L.L.R.M. Medical College,

Meerut (UP), India.

E-mail: gyaneshwertonk@gmail.com,doctoramitsingh15@gmail.com

ABSTRACT: As an elective procedure, total knee arthoplasty is under scrutiny to evaluate clinical and functional outcome. In this regard, we examined 32 knee arthoplasty to assess factors associated with better functional outcome. METHOD: It is a prospective study of 32 knee cases in between 2006-2012. In this 28 knee had osteoarthritis knee and 6 knee had rheumatoid arthritis. Infective, traumatic and metabolic bone disease knees were excluded from study. All patients were evaluated by American knee society score (KSS and functional score).RESULT: Total knee arthoplasty was found to be associated with substantial functional improvement. The greatest amount of improvement is seen within few months after surgery with more gradual improvement occurring up to years of surgery. CONCLUSION: Total knee arthoplasty is a very effective procedure for overall functional improvement and pain relief of the patient with arthritic knee.

KYE WORDS: Total Knee Arthoplasty, Osteoarthritis, Rheumatoid Arthritis, Knee Society Score.

INTRODUCTION: Total knee arthroplasty (TKA) is one of the most commonly performed orthopaedic procedures. Indications for this procedure are knee joint failure secondary to osteoarthritis, rheumatoid arthritis, juvenile rheumatoid arthritis, osteonecrosis and other types of inflammatory arthritis (1). Arthritis of the knee results in loss of functional status and impacts upon independence and quality of life. The primary treatment for patients with end stage arthritis of the knee is total knee arthroplasty (TKA) wherein the knee joint is replaced with a prosthesis. Various treatment options are primarily designed to relieve pain and improve functional status.

Previous reports have suggested that total knee arthroplasty improves functional status and relieves pain with relatively low perioperative morbidity( 2). The threshold for offering total knee replacement (TKR) has not been clearly defined. The general perceived principle has been to delay TKR until the symptoms are at a level where the potential benefits outweigh the potential risks to the individual.

We conducted this study to evaluate the clinical and functional results of total knee arthoplasty, to know the relationship between pre-operative functional score and post- 
operative functional outcome and to know the relationship between functional outcome and time(after surgery) in patients of our institution, who underwent total knee arthroplasty using a single type of implant system

MATERIALS AND METHODS: Between August 2006 and March 2012, nineteen patients of arthritic knee (32knee) were treated with total knee arthoplasty. The study was a prospective study carried out on the patients with arthritic knee, attending the outdoor and the emergency services of the Department of Orthopedics in our institution. The inclusion criteria were; the patients with fifty years and above age group presented with arthritic knee, patients with mature skeleton, patients who did not have other associated bony pathology in ipsilateral limb and the patients who gave their consent to undergo the procedure. The exclusion criteria were patients with arthritic knee with infective, traumatic or metabolic bone diseases etiology, Patient with co-morbid condition which preventing surgical intervention or making patients non compliant for post operative physiotherapy and follow up, patients with local tissue condition making the surgery inadvisable. All the patients were subjected to clinical examination. Radiographic evaluation of the affected and the normal side was done at the time of allotment of study group with the anterior-posterior and lateral views. The radiographs were assessed in terms of involvement of all three compartments of knee and loss of joint space.

All patients were administered combined spinal epidural anesthesia. Our standard practice was to give preoperative prophylactic intravenous antibiotic and usage of tourniquet and unipolar/bipolar diathermy for homeostasis. The TKRs were performed to accept either PFC Sigma or Total Naxgen design, using a medial parapatellar approach, with patella eversion. Softtissue balancing was performed using a sequence of tissue releases, as described by Ritter et al (3) for medial, lateral, and posterior structures.

Thirty two cases (13 bilateral cases, 6 unilateral cases) of total knee replacement, using the PFC Sigma (26 knee) and Total Naxgen (6 knee) prosthesis were performed by a senior consultant between March 2006 to October 2012 . Intra-operative jigs were used on the tibia and the femur to determine the alignment. Bone cuts were made with the aid of the prosthesis specific instrumentation system.

In post operative period, Epidural analgesia was continued for 48 hours. Patients were also wear thrombo-embolic deterrent stockings if required. Those with contraindication to anticoagulants were kept on a low molecular weight heparin until they were ambulatory.

Standard rehabilitation program started at $1^{\text {st }}$ post operative day with passive movement (CPM) and on 3rd day patient was allowed to walk with crutches or walking aids. Physiotherapy with Quadriceps setting, Knee bending, Walker, Stick, Toilet training and Stair climbing done.

Patient related outcomes and clinical evaluations were made by an independent observer. Data obtained from personal interviews and clinical examination was recorded systematically in a Performa. The American Knee Society score (AKS)(4) was used to rate knee function and to determine satisfaction level of each patient. They are intended to provide a score of 0 to 100, where a higher score implies a better outcome. The American Knee Society score is divided into Knee Score and Functional Score and is completed by clinicians.

The knees were assessed clinically in which the main variables examined were pain relief, instability, range of motion and functional improvement. Radiological assessment was by antero-posterior and lateral views of the operated knee. Evidence of loosening was the specific variable assessed (as evidenced by a complete radiolucency of $2 \mathrm{~mm}$ or more about the 
prosthesis at the bone cement interface in cemented arthroplasties). Pain relief was assessed subjectively according to the Knee Society Scale ratings of mild, moderate and severe. Range of movement was measured using a goniometer; clinical instability was similarly assessed with more than 15 degree of varus or valgus (on stressing) constituting significant instability.

Preoperative and postoperative knee scores at 1,6,12 months and subsequent yearly follow up were determined. Postoperative clinical and functional scores were graded as excellent (81 and above) good (71-80) fair (61-70) or bad (60 and above).

RESULTS: A total of 19 patients involving 32 knees were included in the study between March 2006 to October 2012. The primary pathology for 28 knee (87\%) was Osteo- Arthritis (deformity-24 varus, 4 varus +flexion) and 4 Knee (13\%) had Rheumatoid arthritis (deformity3 varus; 1 valgus). Of the 32 knee that were recruited, $56 \%$ or 18 knee were female and $44 \%$ or 14 knee were male. The mean age of patients at the time of surgery was 61.3 years (range 51-75 years). Thirteen patients had bilateral total knee replacement whilst Six patients had unilateral total knee replacement. PFC Sigma (26 knee) and Total Naxgen(6 knee) prosthesis were used. All were posterior cruciate ligament sacrificing prosthesis.

The follow up period vary between 6 months to 6 years, with mean follow up was 1 year 6 months.

The mean American Knee Society score at pre-op was 31.2 (standard deviation 9.54), mean post-op score was 87.26(standard deviation 9.52) with 100\% (32 knees) rated excellent and none rated poor. The ASK scores ranged from 63 to 95.

The mean Function Score in pre-op period was 9.7 (standard deviation 7.06), mean post-op score was 74.74 (standard deviation19.31) with 93.4\% (30 knee) rated excellent ,6.25\% (2 knee) rated good and none rated poor. In this prospective study we have preoperative knee scores to compare with the final knee scores .All finding were statistically tested and significant.(see table 1 and 2)

Per operative complication was noted in one case. This was deficient medial femoral condyle (had to be built up with bone graft). There was no evidence of polyethylene wear or osteolysis at the time of review. There was no case of aseptic loosening or anterior knee pain in this study.

\begin{tabular}{|c|c|c|c|c|c|c|}
\hline \multicolumn{2}{|c|}{ PAIR } & MEAN & $\mathbf{N}$ & $\begin{array}{l}\text { STANDARD } \\
\text { DEVIATION }\end{array}$ & $\begin{array}{l}\text { STANDARD } \\
\text { ERROR OF } \\
\text { MEAN }\end{array}$ & $\begin{array}{l}\text { SIGNIFICANS } \\
\text { E }\end{array}$ \\
\hline PAIR & KSCO-PRE-OP & 31.22 & 32 & 9.54 & 1.69 & .0001 \\
\hline 1 & $\begin{array}{l}\text { KSCO-POST-OP } \\
1 \text { MONTH }\end{array}$ & 78.03 & 32 & 11.57 & 2.04 & \\
\hline PAIR & KSCO-PRE-OP & 31.22 & 32 & 9.54 & 1.69 & .0001 \\
\hline 2 & $\begin{array}{l}\text { KSCO-POST-OP } \\
6 \text { MONTH }\end{array}$ & 91.41 & 32 & 2.51 & 0.44 & \\
\hline PAIR & KSCO-PRE-OP & 31.22 & 32 & 9.54 & 1.69 & .0001 \\
\hline 3 & $\begin{array}{l}\text { KSCO-POST-OP } \\
12 \text { MONTH }\end{array}$ & 92.34 & 32 & 2.36 & 0.42 & \\
\hline & & & & & & \\
\hline
\end{tabular}

(Table-1) 
Paired t-test of functional score table

\begin{tabular}{|c|c|c|c|c|c|c|}
\hline \multicolumn{2}{|c|}{ PAIR } & \multirow{2}{*}{$\begin{array}{l}\text { MEAN } \\
9.69\end{array}$} & \multirow{2}{*}{$\mathbf{N}$} & \multirow{2}{*}{$\begin{array}{l}\text { STANDARD } \\
\text { DEVIATION } \\
7.06\end{array}$} & \multirow{2}{*}{$\begin{array}{l}\text { STANDARD } \\
\text { ERROR OF } \\
\text { MEAN } \\
1.25\end{array}$} & \multirow{2}{*}{$\begin{array}{l}\text { SIGNIFICANS } \\
\text { E } \\
.0001\end{array}$} \\
\hline PAIR & FSCO -PRE-OP & & & & & \\
\hline 1 & $\begin{array}{l}\text { FSCO -POST-OP } \\
1 \text { MONTH }\end{array}$ & 51.09 & 32 & 12.36 & 2.19 & \\
\hline PAIR & FSCO -PRE-OP & 9.69 & 32 & 7.06 & 1.25 & .0001 \\
\hline 2 & $\begin{array}{l}\text { FSCO -POST-OP } \\
6 \text { MONTH }\end{array}$ & 86.56 & 32 & 7.87 & 1.39 & \\
\hline PAIR & FSCO -PRE-OP & 9.69 & 32 & 7.06 & 1.25 & .0001 \\
\hline 3 & $\begin{array}{l}\text { FSCO -POST-OP } \\
12 \text { MONTH }\end{array}$ & 86.56 & 32 & 7.87 & 1.39 & \\
\hline & & & & & & \\
\hline
\end{tabular}

(Table-2)

DISCUSSION: Functional results of total knee arthoplasty are good to excellent in Early post- op period. In one month post-op period patient could achieve a good range of motion with gradual relief from pain. There are large differences in pre-op functional score and post-op functional score of one month. In few months, patient report complete relief from pain and achieved maximum functional outcome. By six post-op month maximum patient could get optimum outcome. (as shown in functional score graph-gap between post-op 1 month and post op 6 month).

Functional Score of patients indicate that in patients with lower preoperative score, function and pain were not improved postoperatively to the level achieved by those with higher preoperative score. Patients with knee Osteoarthritis (OA) and lower preoperative function failed to attain similar functional levels postoperatively as those with higher preoperative function. Therefore, it appears that earlier intervention in the course of the natural history of knee $\mathrm{OA}$ allowed for a better postoperative outcome at 6 months. Traditional orthopedic practice, to delay surgery as long as possible, should be reevaluated in view of these data. Further research should investigate whether there is a threshold level of functional decline after which knee replacement should be done.

Recovery of function after total knee replacement (TKR) is dependent on a number of factors, including range of movement, muscle strength, joint stability and pain, as well as issues influencing the patient's general health, sense of wellbeing and expectations (5-7) Understanding the predictors of outcome after TKR may help identify patients that need additional assistance in rehabilitation. Gender, body mass index, and co-morbidities account for $42 \%$ of the variance in function after surgery (9). Elderly patients with marked functional impairment, severe pain, a high body mass index, and major co-morbidities are more likely to have worse postoperative outcomes (8-12). Careful selection of elderly patients for joint replacement is essential, as mortality and complication rates increase with age (10-12). 
Likewise, severe preoperative pain and multiple co morbidities are predictors of poor outcome (13).TKA can provide excellent pain relief and restoration of function for patients. This study showed that most patients achieved good to excellent early results with the treatment. Independent of baseline pain or function, a higher education level was associated with less pain and better function at 6 months after surgery. The role of education or that of socioeconomic status needs to be controlled for when postoperative pain and/or function is chosen as an outcome in studies that measure the impact of knee replacement surgery.

Our patient outcomes compared favorably to another study of Ip D, Wu WC, Tsang WL, reporting early results of 48 patients with 60 knees treated with posterior stabilized TKR where the mean post operative Knee Score was 85 (70-100) and the mean Functional Score was 70 (55-100) (14). Diduch, Insall et al reported a series of 103 patients with cemented TKRs using a posterior stabilized design followed up for an average of 8 years. The average clinical score at follow up was 94 points and the functional score 89 points. High functional scores could be attributed to the fact that all were relatively young patients with no underlying medical condition. Li PL, Zamora J et al reviewed the outcome of 94 knees in 78 patients with total condylar type prosthesis. Results at ten years of follow up revealed a mean clinical score of 87 (87.6 in our study) and a mean functional score of 56 (74.4 in our study)(16)

The introduction of computer-assisted surgery using a Navigation system and minimally invasive surgery techniques reduces the trauma and recovery time (17). As a result, accelerated rehabilitation can be initiated and functional ability can be improved. The use of a navigation system is expected to lead to greater consistency of clinical results in addition to minimizing problems such as alignment error and bony preparation error. $(18,19)$

Our study was limited by involvement of only one center. We recognize that there may be considerable variation in practice style and patient characteristics. We have not been able to collect post operative information on patients who dropped out of the study. Longer-term functional outcomes could not be studied here. Cemented prostheses may be associated with less pain and more rapid recovery postoperatively. Our study design does not allow us to study definitively the impact of cemented components in functional recovery.

CONCLUSION: The early result of the TKR was good to excellent in most patient. Study and follow up are still going on to conclude the final outcome .But clinical and statistical significance of the study indicate favorable outcome of TKR. Most of the patients were functionally independent, had no knee pain and were satisfied with their outcomes.

\section{REFERENCES:}

1. Rankin EA, Alarcon GS, Chang RW, Cooney LM, Costley LS, Delitto A, et al. NIH consensus statement on total knee replacement December 8-10, 2003. J Bone Joint Surg Am, 86: 1328-35.

2. Callahan CM, Drake BG, Heck DA, Dittus RS. Patient outcomes following tricompartmental total knee replacement. A meta analysis. JAMA, 1994; 271(17): 134957.

3. Ritter MA, Harty LD, Davis KE, Meding JB, Berend ME.Predicting range of movement after total knee arthroplasty: clustering log-linear regression, and regression tree analysis. J Bone Joint Surg [Am]2003;85-A:1278-85.

4. Insall JN, Dorr LD, Scott RD, Scott NW. Rationale of the Knee Society clinical rating system. Clin Orthop Relat Res, 1989; 248:13-4. 
5. Mizner RL, Petterson SC, Stevens JE, Axe MJ, Snyder-Macker L. Preoperative quadriceps strength predicts functional ability one year after total knee arthroplasty.J Rheumatol 2005;32:1533-9.

6. Parent E, Moffet H.Preoperative predictors of locomotor ability two months after total knee arthroplasty for severe osteoarthritis.Arthritis Rheum2003;49:36-50.

7. Maohomed NN, Liang MH, Cook EF, et al.The importance of patient expectations in prediction functional outcomes after total joint arthroplasty.J Rheumatol2002;29:12739.

8. Belmar CJ, Barth P, Lonner JH, Lotke PA. Total knee arthroplasty in patients 90 years of age and older. J Arthroplasty1999;14:911-4.

9. Parent E, Moffet H. Preoperative predictors of locomotor ability two months after total knee arthroplasty for severe osteoarthritis. Arthritis Rheum 2003;49:36-50.

10. Wells V, Hearn T, Heard A, Lange K, Rankin W, Graves S. Incidence and outcomes of knee and hip joint replacement in veterans and civilians. ANZ J Surg 2006;76:295-9.

11. Kennedy LG, Newman JH, Ackroyd CE, Dieppe PA. When should we do knee replacements? Knee 2003;10:161-6.

12. Kreder HJ, Grosso P, Williams JI, Jaglal S, Axcell T, Wal EK, et al. Provider volume and other predictors of outcome after total knee arthroplasty: a population study in Ontario. Can J Surg 2003;46:15-22.

13. Weng HH, Fitzgerald J. Current issues in joint replacement surgery. Curr Opin Rheumatol 2006;18:163-9.

14. Ip D, Wu WC, Tsang WL: Early results of posterior-stabilised NexGen Legacy total knee arthroplasty. J Orthop Surg (Hong Kong), 2003: 11(1): 38-42.

15. Diduch DR Insall J . TKR in young active patients long term follow up \& functional outcome JBJS A 79:4 575-82 1997

16. Li PL Zamora J . The results at ten years of the insall Burstein II total knee replacement clinical Radiological and survivorship studies JBJS B-81:4 pp 647-53 Jul 1999

17. Klein GR, Restrepo C, Hozack WJ. The effect of knee component design changes on range of motion evaluation in vivo by a computerised navigation system. J Arthroplasty, 2006; 21(5): 623-7.35

18. Mason JB, Fehring TK, Estok R, Banel D, Fahrbach K. Meta analysis of alignment outcomes in computer-assisted total knee arthroplasty surgery. J Arthroplasty 2007;22:1097-1106.

19. Brin YS, Nikolaou VS, Joseph L, Zukor DJ, Antoniou J. Imageless computer assisted versus conventional total knee replacement: a Bayesian meta-analysis of 23comparative studies. Int Orthop2011;35:331-339. 


\section{ORIGINAL ARTICLE}

\section{Knee society score relationship(part-1)}

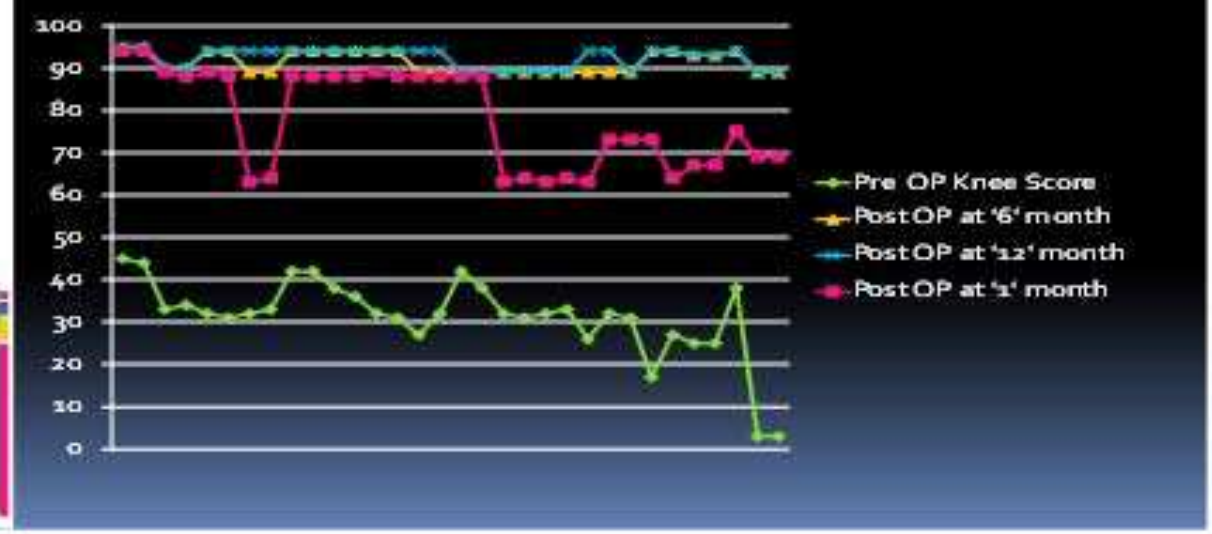

\section{Knee Society functional score relationship}

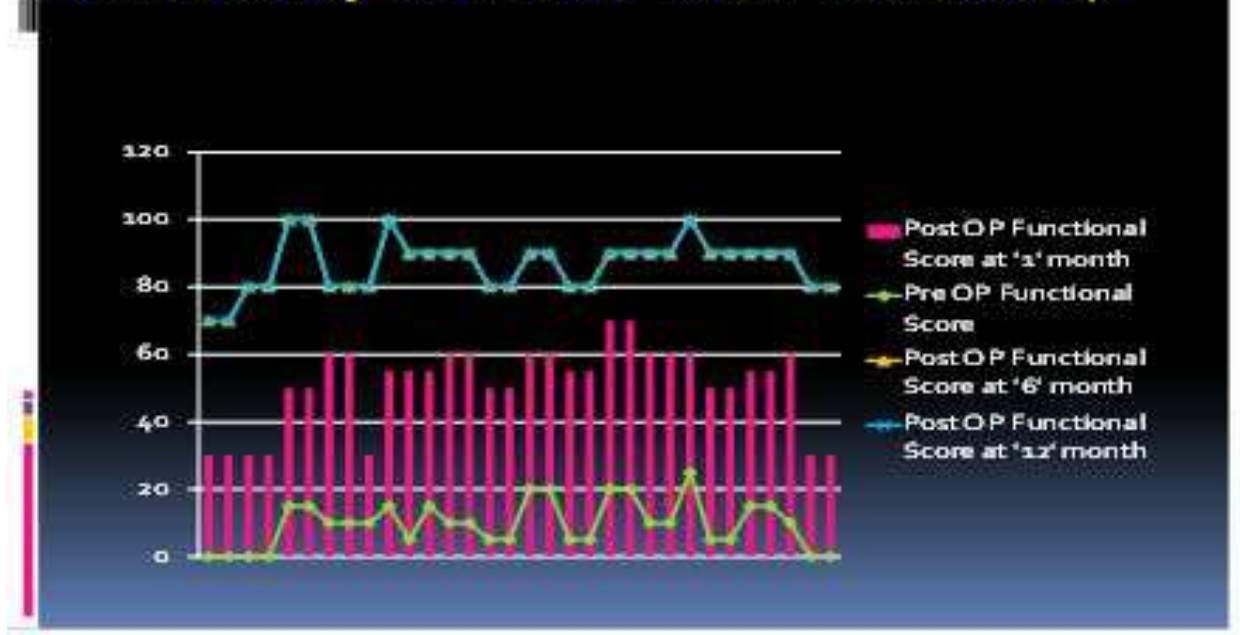




\section{ORIGINAL ARTICLE}

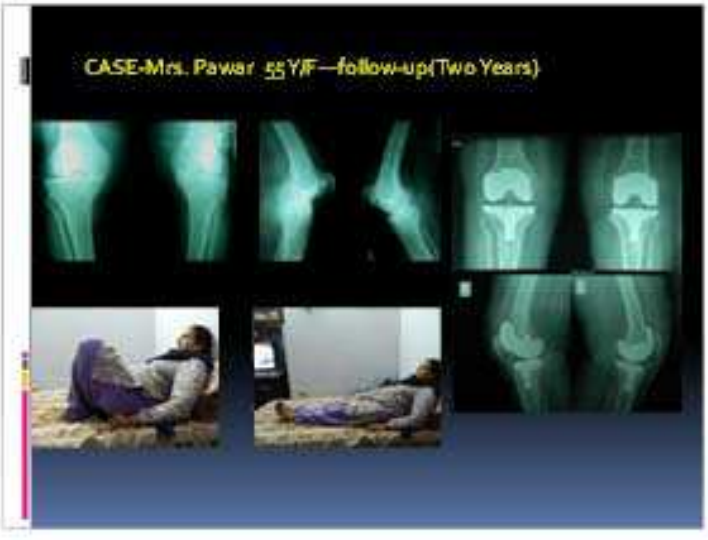

CASE-SHAHOALAN-5AY/F(VALGUS DEFORMITY)
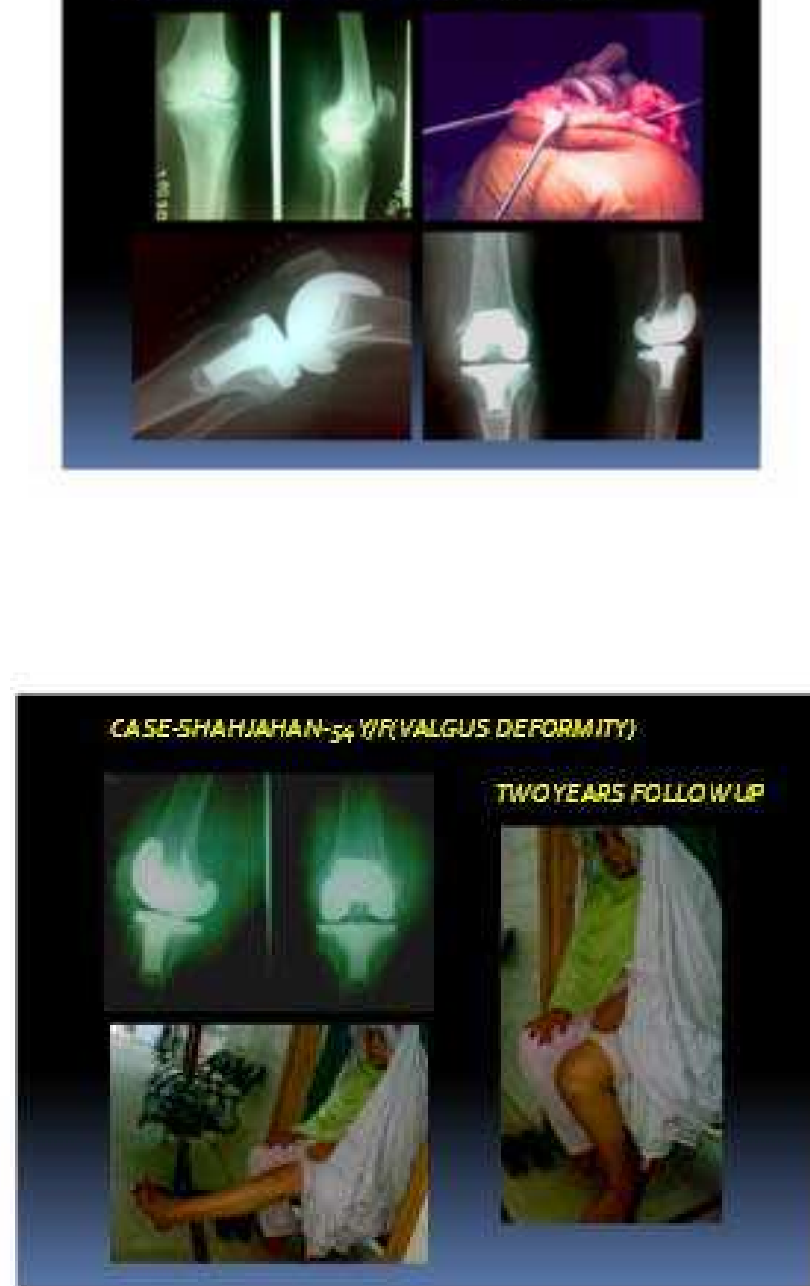